\title{
Ventricular Septal Defect
}

\author{
Mary Etta King, MD \\ Michael de Moor, MD
}

\author{
Address \\ Harvard Medical School and Massachusetts General Hospital, 55 Fruit \\ Street, VBK 615, Boston, MA 02114-2696, USA.
}

Current Treatment Options in Cardiovascular Medicine 1999, 1:311-322

Current Science Inc. ISSN 1092-8464

Copyright $\odot 1999$ by Current Science Inc.

\section{Opinion statement}

Ventricular septal defects (VSDs) are the most common congenital heart malformations seen in children. Because spontaneous closure occurs frequently, patients with small VSDs should be followed clinically with no limitations except endocarditis prophylaxis. Surgical closure is recommended for only small defects with significant associated lesions such as aortic regurgitation, aortic valve prolapse, right or left ventricular outflow obstruction, tricuspid regurgitation, left ventricle to right atrial shunt, or recurrent endocarditis. Enlarging left ventricular size or deteriorating left ventricular function would also be an indication for surgical repair. Moderate and large VSDs in infancy often require treatment of congestive heart failure with diuretics, digitalis, and afterload reduction. Surgical closure before 9 months of age is indicated for large VSDs and by 2 years of age for moderate shunts to prevent pulmonary vascular obstructive disease and the consequences of long-standing volume overload. Device closure of VSD is still in the investigational stage but holds promise for treatment of apical or multiple muscular VSDs.

\section{Introduction}

Ventricular septal defect is the most common congenital cardiac malformation found in children, occurring with an incidence as high as 5.6 per 1000 live births when sensitive color-flow Doppler imaging is used as the diagnostic technique $[1,2 \bullet \bullet]$. Ventricular septal defects may occur as one component of a more complex cardiac malformation (eg, tetral ogy of Fal lot, double-outlet right ventricle, atrioventricular septal defect) or as the primary pathologic abnormality. This discussion focuses on treatment options for isolated VSD.

The interventricular septum is conceptually a simple structure separating the right and left ventricles. It is anatomically and embryologi cally complex, however, evolving from fusion of the endocardial cushions at the crux of the heart with the muscle mass between the devel oping ventricles and with the conal septum growing downward from the devel oping arterial trunk. The completed interventricular septum is a multifaceted structure composed of both membranous and muscular portions (Fig. 1). The inlet septum is the smooth-walled portion that extends from the tricuspid val ve annulus to the insertion site of the val ve leaflets. The trabecular or muscular septum is the coarsely trabec- ulated region that extends from the midventricle to the apex and anteriorly toward the outflow tracts. The infundibular septum begins above the septal band and extends to the pulmonary annulus. Tucked between the inlet septum, the infundibular septum, and the trabecular septum is a small fibrous area just beneath the aortic val ve termed the membranous septum. The classification of defects in the interventricular septum has not been standardized but is generally based on the location of the defect or the portion of the septum that is deficient. In this article, we use the nomenclature shown in Figure 2.

\section{ASSOCIATED LESIONS}

Localization of a VSD is more than an academic exercise because it determines the type of associated complications as well as the likelihood of spontaneous cl osure. Inlet VSDs, for example, are often associated with abnormal devel opment of the atrioventricular valves, either as part of an endocardial cushion defect or rel ated to a straddling or overriding atrioventricular val ve Trabecular defects may be multiple - the so-called "Swiss cheese" septum-but al so have the highest rate 


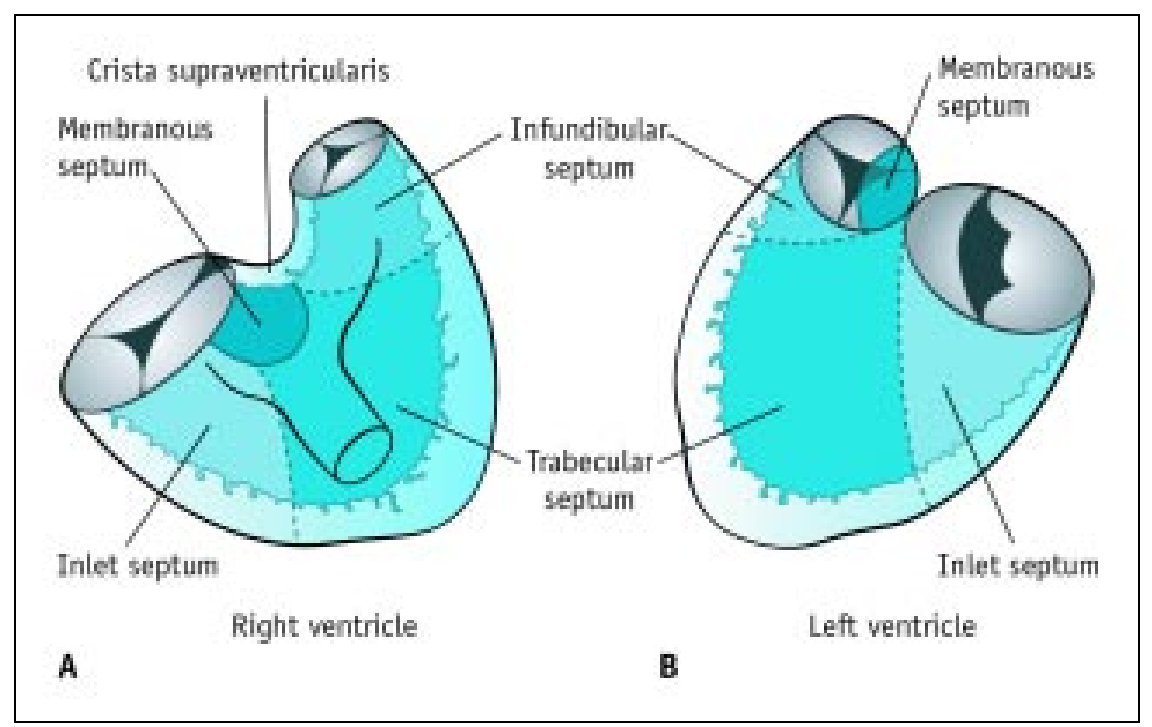

Figure 1. The interventricular septum as viewed from right $(A)$ and left (B) ventricular aspects.

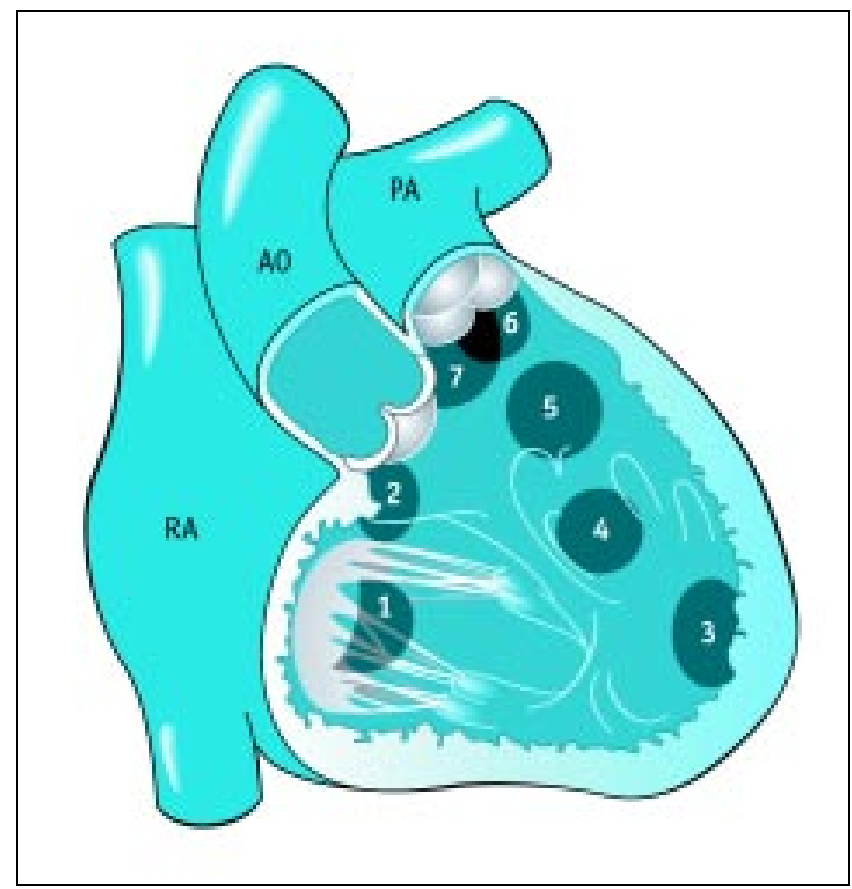

Figure 2. The interventricular septum as viewed from the right ventricle to indicate the location and classification of ventricular septal defects. 1: Inlet defect; 2: perimembranous defect; 3-5: muscular/trabecular defect; 6- 7: subarterial defect. AO- aorta; PA - pulmonary artery; RA - right atrium.

of spontaneous closure (80\%). A perimembranous VSD may occur with discrete membranous subaortic stenosis and an obstructive right ventricular muscle bundle Perimembranous VSDs al so undergo cl osure by formation of a membranous septal aneurysm, which incorporates tricuspid val ve tissue and may result in tricuspid regurgitation or left ventride to right atrial shunting. Subarterial defects are often associated with prolapse of an adjacent aortic valve cusp into the defect with subsequent aortic insufficiency.

\section{DIAGNOSIS}

Diagnosis of ventricular septal defect is suggested by the typical auscultatory finding of a coarse systolic murmur audible at the left sternal border after the first few days of life Two-dimensional echocardiography with Doppler color-flow mapping has now become the definitive diagnostic modality for detecting and characterizing VSDs, their associated complications, the size of the shunt, and the estimated pulmonary artery pressure (Figs. 3 and 4). Recent devel opments in three-dimensional echocardiography are being applied to the diagnosis of VSD, yielding the promise of better spatial understanding of defect size and location [4]. In most institutions, echocardiography in experienced hands has obviated the need for cardiac catheterization in the pediatric patient with an isolated VSD of small or moderate size and no other complications [5]. Diagnostic catheterization is best reserved for older patients with a large VSD and pulmonary hypertension to assess the reactivity of the pulmonary vasculature or to characterize further associated lesions of significance

\section{TREATMENT OVERVIEW}

The natural history of a small VSD includes a clinical course in which the patient is usually asymptomatic with normal growth and normal exercise tolerance. Spontaneous closure may occur in 35\% to $40 \%$ of patients, most often in the first 2 years of life, with a continued $10 \%$ rate of closure in adolescence and adulthood $[6,7,8 \cdot]$. Congestive heart failure and pulmonary hypertension do not occur, but bacterial endocarditis is a small though definite risk (12 per 10,000 personyears) $[9 \bullet \bullet$. Thus, the patient with a small VSD can be managed expectantly with endocarditis prophylaxis and clinical follow-up every 2 to 5 years [10•].

The natural history is less benign when a small VSD is associated with aortic prolapse, aortic regurgitation, discrete subaortic stenosis, right ventricular outflow obstruc- 


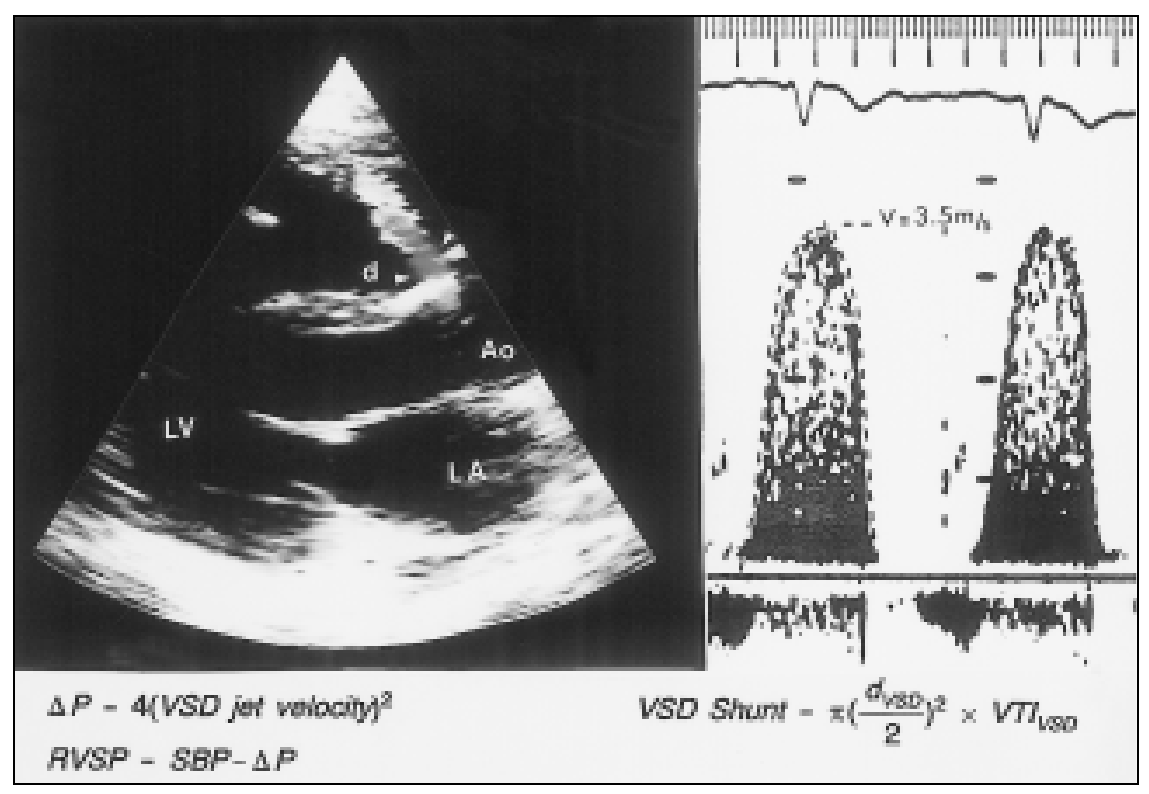

Figure 3. Echo Doppler findings with a restrictive perimembranous ventricular septal defect (VSD). Two-dimensional echo (left) demonstrating a Doppler color flow jet through the septum just below the aortic valve. The size of the VSD can be approximated by the diameter of the jet (d) as it passes through the defect. A continuous-wave Doppler spectral tracing (right) of the VSD jet. The peak velocity of this flow predicts the pressure gradient across the interventricular septum using the modified Bernoulli equation: $\Delta \mathrm{P}=4$ (velocity) ${ }^{2}$. Right ventricular systolic pressure (RVSP) can then be calculated: RVSP = systemic blood pressure - $\Delta \mathrm{P}$. Shunt size can also be estimated by calculating the product of the velocity time integral (dotted lines in $B$ ) and the VSD flow area - II (d/2) ${ }^{2}$. AO- aorta; LA- left atrium; LV- left ventricle. (From King [3]; with permission.)

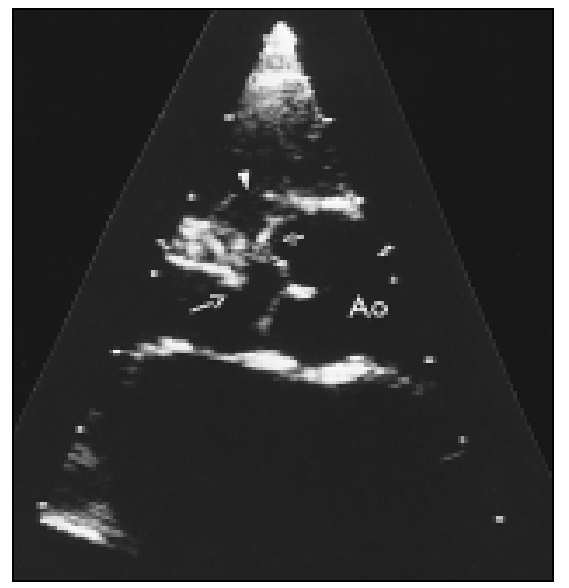

Figure 4. Two-dimensional echocardiographic image of the parasternal long axis of the left ventricular outlet tract demonstrating aortic valve prolapse of the right coronary cusp (small arrow) into a perimembranous ventricular septal defect. A membranous septal aneurysm is apparent on the right septal surface (carat), and a small subaortic tag is shown protruding into the outflow tract just below the aortic valve (large arrow). Ao- aorta.

tion, significant tricuspid regurgitation, or left ventride to right atrial shunting. Surgical closure of the VSD should be considered when the hemodynamic consequences of the associated lesion are clinically significant. Many centers recommend closure of the small subarterial VSD whenever aortic leaflet prolapse is present to prevent the development of significant aortic insufficiency [11].

Moderate and large ventricular septal defects often cause congestive heart failure in early infancy, requiring pharmacologic management. The chronic vol ume overload on the left ventride and pulmonary overcirculation lead to frequent respiratory infections and poor weight gain. Elevation of pulmonary vascular resistance may reduce shunt size and congestive symptoms but may al so result in irreversible pulmonary vascular obstructive disease (PVOD) if the defect is not repaired [12]. A small percentage of these larger defects will undergo spontaneous dosure or reduction in shunt size, but most will require closure before the age of 2 years. The majority of patients with large VSDs can safely undergo primary surgical repair in experienced centers at any time in the first year of life $[13,14]$. Staged repair with palliative pulmonary banding early in infancy and later definitive repair is rarely appropriate except perhaps with extreme prematurity, significant lung disease, or a coexisting disorder for which cardiopul monary bypass is contraindicated [15]. Multiple trabecular VSDs may still be managed by initial pulmonary artery banding but areal so being successfully closed primarily at surgery and with transcatheter devices [16,17]. Management of VSD with significant pulmonary hypertension requires careful assessment of the reactivity of the pulmonary vascular bed before operative closure is chosen $[18,19]$.

\section{Treatment}

\section{Diet and lifestyle}

- Nutritional issues are of most concern in the infant or child with unrepaired VSD and congestive heart failure Patients with large left-ro-right shunts have an increased metabolic rate and increased oxygen consump- 
tion. The tachycardia and tachypnea, labored respirations, and sweating contribute to an increase in energy expenditure. These same congestive symptoms al so impair the infant's ability to ingest food. Elevated venous pressure secondary to heart failure may cause mucosal edema and incomplete absorption of ingested nutrients. Acquired respiratory infections impose an added metabolic burden. Thus, in the infant and child with a moderate or large VSD, careful attention to feeding patterns and growth is an integral part of medical management.

- The urge to restrict fluids because of congestive heart failure must be resisted when this results in inadequate cal oric intake. Energy requirements as high as $170 \mathrm{kcal} / \mathrm{kg} / \mathrm{d}$ may be necessary for normal growth [20]. These needs may be met with frequent feedings using infant formul as with high caloric density ( $24 \mathrm{cal} / \mathrm{oz}$ ) and with supplementation of medium-chain triglycerides and diluted infant cereals.

- Attention to sodium content is al so important, but the unpalatability of low-sodium formulas may limit their acceptance. An increase in diuretic therapy may be needed to compensate for the volume of oral formula necessary to supply adequate calories.

- In some infants with severe failure to thrive, short-term nasogastric feeding may be needed to improve nutritional status prior to correctivesurgery [27].

- Management of patients with an isolated VSD depends on the size of the VSD and subsequently the amount of left-to-right shunting and the degree of pulmonary hypertension or pulmonary vascular obstructive disease Other factors that need to betaken into consideration arethe presence of associated defects, such as coarctation of the aorta, aortic or subaortic stenosis, aortic regurgitation, mitral regurgitation, or pulmonary or subpulmonary stenosis. The presence of any of these lesions may affect management and the planning for surgery. When considering the management of isolated VSD, the pediatric cardiologist plots a strategy for the future based on whether the VSD is small, moderate, or large and nonrestrictive (Table 1).

- The small VSD usually presents in an asymptomatic child with a systolic murmur and nomal electrocardiographic findings. Usually, no medical therapy is required, and spontaneous closure occurs in approximately $40 \%$ of cases of perimembranous VSD and $80 \%$ of cases of muscular trabecular VSDs. With all VSDs, there is a risk of infective endocarditis. Meticulous dental care is therefore important, and antibiotic prophylaxis is necessary for dental, respiratory tract, gastrointestinal, and urogenital procedures [22 ••].

Table 1. Simplified severity grading of isolated ventricular septal defects

\begin{tabular}{ll}
\hline Small & Pulmonary: systemic pressure ratio $<0.3$ \\
Moderate & Qp:Qs $<1.5$ \\
& Pulmonary:systemic pressure ratio $<0.66$ \\
Large/ nonrestrictive & Pus $>1.5$ \\
& Pulmonary:systemic pressure ratio $>0.66$ \\
& Qp:Qs $>2.0$ until pulmonary vascular obstructive \\
& disease develops
\end{tabular}


- The moderate-sized VSD is generally managed medical ly in thefirst year of life to assess whether spontaneous closure or some restriction in size will occur. Medical therapy is initiated with a diuretic such as furosemide given twice a day to control the signs and symptoms of heart failure. When furosemidealone is used to treat heart failure, potassium-sparing agents such as spironolactone may be necessary. Other diuretics that may be used include hydrodiuril or, occasionally, ethacrynic acid. If there is inadequate response to a diuretic alone, then angiotensin-converting enzyme (ACE) inhibitors may be added. They have a beneficial clinical effect and in the cardiac catheterization laboratory have been shown to decrease the pulmonary-tosystemic flow ratio. Enalapril is effective in a once-daily dose[23]. It should be started at a low dose and increased gradually to ensure that hypotensive episodes do not develop. ACE inhibitors have the additional benefit of being potassium sparing, obviating the need for the addition of spironolactone to the medical regimen. If the heart failure remains uncontrolled, digoxin is frequently used as the next conventional line of management, although its use may be controversial $[24,25]$. Patients with a large left-toright shunt generally have normal or hypernormal ventricular function. There is decreased sensitivity of the newborn myocardium to digoxin. On the other hand, digoxin has been used for several decades owing to its apparent clinical effect. Medical therapy can be weaned if it becomes apparent that the VSD is becoming smaller and more restrictive. This is suspected clinically if the systolic murmur becomes louder, the pulmonary component of the second heart sound becomes softer (indicating normalization of the pulmonary artery pressures), the middiastolic rumble disappears (indicating that the Qp:Qs is less than 2:1), and the heart decreases in size on the chest radiograph.

- Although thelarge non restrictive VSD will require surgical closure in the first year of life, the patient is usually managed with medical therapy with diuretics, ACE inhibitors, and digoxin until approximately 4 to 6 months of age Nutritional supplementation is frequently necessary because of the increased metabolic demand in heart failure in infants. Some degree of failure to thrive (FIT) is al most invariable in infants with a large VSD; in fact, theabsence of FIT should alert the clinician to the possible development of pulmonary vascular obstructive disease, which by increasing the pulmonary vascular resistance causes less left-to-right shunting. Increasing pulmonary resistance should al so be suspected if the infant becomes less tachypneic, the second heart sound is increased in intensity, the middiastolic rumble becomes softer, or the heart becomes smaller on chest radiography.

- Neonates and infants may occasionally develop such severe cardiac and respiratory failure that intubation and ventilation are necessary. This is especially true if the initial presentation is associated with pneumonia or if there are other cardiac defects such as left ventricular outflow tract obstruction, patent ductus arteriosus, or atrial septal defect. It is vital to avoid hyperoxygenation or hyperventilation in these patients, because this will result in a fall in pulmonary vascular resistance and hence an increase in the left-to-right shunt. In such critically ill infants, diuretics and digoxin should be given intravenously. If the infant cannot be weaned from ventilatory support, early surgical intervention may be required.

Furosemide

Standard dosage 0.5 to $1 \mathrm{mg} / \mathrm{kg}$ per dose given every 6 to 12 hours depending on the severity of the heart failure; may be given via oral, intramuscular, or intravenous route. If given as an infusion, the dose is 0.1 to $1 \mathrm{mg} / \mathrm{kg} / \mathrm{h}$.

Contraindications Anuria, hypersensitivity to furosemide. 
Main drug interactions Increases the ototoxic effects of aminoglycosides; potentiates antihypertensive agents and salicylates; antagonizes the skeletal muscle-relaxing effect of tubocurarine; and potentiates the action of succinylcholine.

Main side effects Hypokalemia, hyperglycemia and hyperuricemia, orthostatic hypotension, and gastrointestinal symptoms. Hematologic reactions and central nervous system symptoms including paresthesias, vertigo, and headache are uncommon.

Cost/cost effectiveness Furosemide is an inexpensive, effective diuretic. It is available as an oral solution for about $\$ 10$ per $60 \mathrm{~mL} ; 100$ tablets of 20 - $\mathrm{mg}$ strength cost $\$ 5$ to $\$ 10$.

Spironolactone

Standard dosage For a patient weighing 3 to $10 \mathrm{~kg}, 6.25 \mathrm{mg}$ is given orally every 12 hours. For a patient weighing 11 to $20 \mathrm{~kg}, 12.5 \mathrm{mg}$ is given orally every 12 hours. For a patient weighing 21 to $40 \mathrm{~kg}, 25 \mathrm{mg}$ is given orally every 12 hours. For a patient weighing more than $40 \mathrm{~kg}, 25 \mathrm{mg}$ is given orally every 8 hours.

Contraindications Anuria or acute renal insufficiency or hyperkalemia.

Main drug interactions Potentiates the antihypertensive effects of other diuretics and increases the half-life of digoxin.

Main side effects Gynecomastia, cramping and diarrhea, drowsiness and headache, rashes, drug fever, and ataxia.

Cost/cost effectiveness Spironolactone is an inexpensive diuretic used for its potassium-sparing effect. A supply of 100 tablets of 25 -mg strength costs about $\$ 10$.

Enalapril

Standard dosage 0.1 to $1.0 \mathrm{mg} / \mathrm{kg}$ daily given orally. Start at a low dose and increase gradually, being sure to monitor the blood pressure. Administration is effective once daily in infants, but older children may require the same daily dose divided every 12 hours.

Contraindications Hypersensitivity to enalapril, history of angiotensin-converting-enzyme-inhibitor angioedema, pregnancy.

Main drug interactions Hypotension, especially patients on diuretic therapy. Attenuates potassium loss of other diuretics.

Main side effects Anaphylactoid reactions, dry cough, hypotension, hyperkalemia, transient reversible increase in creatinine and blood urea nitrogen levels, and toxicity to the fetus in the second and third trimesters of pregnancy.

Cost/ cost effectiveness Enalapril is a cost-effective ACE inhibitor that is more expensive than captopril but can be administered less frequently. The cost of 100 tablets of 5 -mg strength is about $\$ 100$.

Standard dosage See Table 2. For acute treatment of congestive heart failure in the infant or child, determine the total digitalizing dose (TDD) and give $1 / 2$ the TDD initially, then $1 / 4$ every 8 to 18 hours for two doses. After initial digitalization, determine the daily maintenance dose and divide it into two daily doses for children younger than 10 years of age, one daily dose for children older than 10 years. Obtain an electrocardiogram about 6 hours after each dose to detect toxicity. For more stable outpatients, determine the daily maintenance dose and begin oral administration; full digitalization is expected in 4 to 7 days.

Contraindications Hypersensitivity to digoxin, ventricular dysrhythmia, or hypokalemia. Dosage should be modified in renal failure. Care should be taken with active carditis because arrhythmias are common.

Main drug interactions Care should be taken with the concomitant use of potassium-depleting drugs, which may predispose to arrhythmia. Various drugs may increase the serum digoxin concentration or increase its absorption. Consult the pharmacy for specific interactions.

Main side effects Arrhythmias, anorexia, diarrhea, vomiting, visual disturbances, and gynecomastia. Side effects are uncommon in young children. 


\section{Table 2. Dosages for digoxin}

\begin{tabular}{|c|c|c|}
\hline Age & Total digitalizing dose & Daily maintenance dose \\
\hline Premature infant & $20 \mu \mathrm{g} / \mathrm{kg}$ po & $5 \mu \mathrm{g} / \mathrm{kg} \mathrm{po}$ \\
\hline Term infant & $30 \mu \mathrm{g} / \mathrm{kg}$ po & $8-10 \mu \mathrm{g} / \mathrm{kg}$ po \\
\hline$<2 y$ & $\begin{array}{l}20 \mu \mathrm{g} / \mathrm{kg} / \mathrm{V} / \mathrm{M} \\
40-50 \mu \mathrm{g} / \mathrm{kg} \text { po }\end{array}$ & $\begin{array}{l}6-8 \mu \mathrm{g} / \mathrm{kg} / \mathrm{V} / \mathrm{M} \\
10-12 \mu \mathrm{g} / \mathrm{kg} \mathrm{po}\end{array}$ \\
\hline & $30-40 \mu \mathrm{g} / \mathrm{kg}$ IV/IM & $7-9 \mu \mathrm{g} / \mathrm{kg}$ IV/IM \\
\hline $2-10 y$ & $\begin{array}{l}30-40 \mu \mathrm{g} / \mathrm{kg} \text { po } \\
20-30 \mu \mathrm{g} / \mathrm{kg} \text { IV/IM }\end{array}$ & $\begin{array}{l}\text { 8-10 } \mu \mathrm{g} / \mathrm{kg} \mathrm{po} \\
6-8 \mu \mathrm{g} / \mathrm{kg} \mathrm{IV} / \mathrm{IM}\end{array}$ \\
\hline$>10 y$ & $\begin{array}{l}0.75-1.25 \mathrm{mg} \mathrm{po} \\
0.75-1.25 \mathrm{mg} \text { IV/IM }\end{array}$ & $0.125-0.25 \mathrm{mg} \mathrm{po}, \mathrm{IV}$, or IM \\
\hline
\end{tabular}

\section{Table 3. Indications for surgical closure}

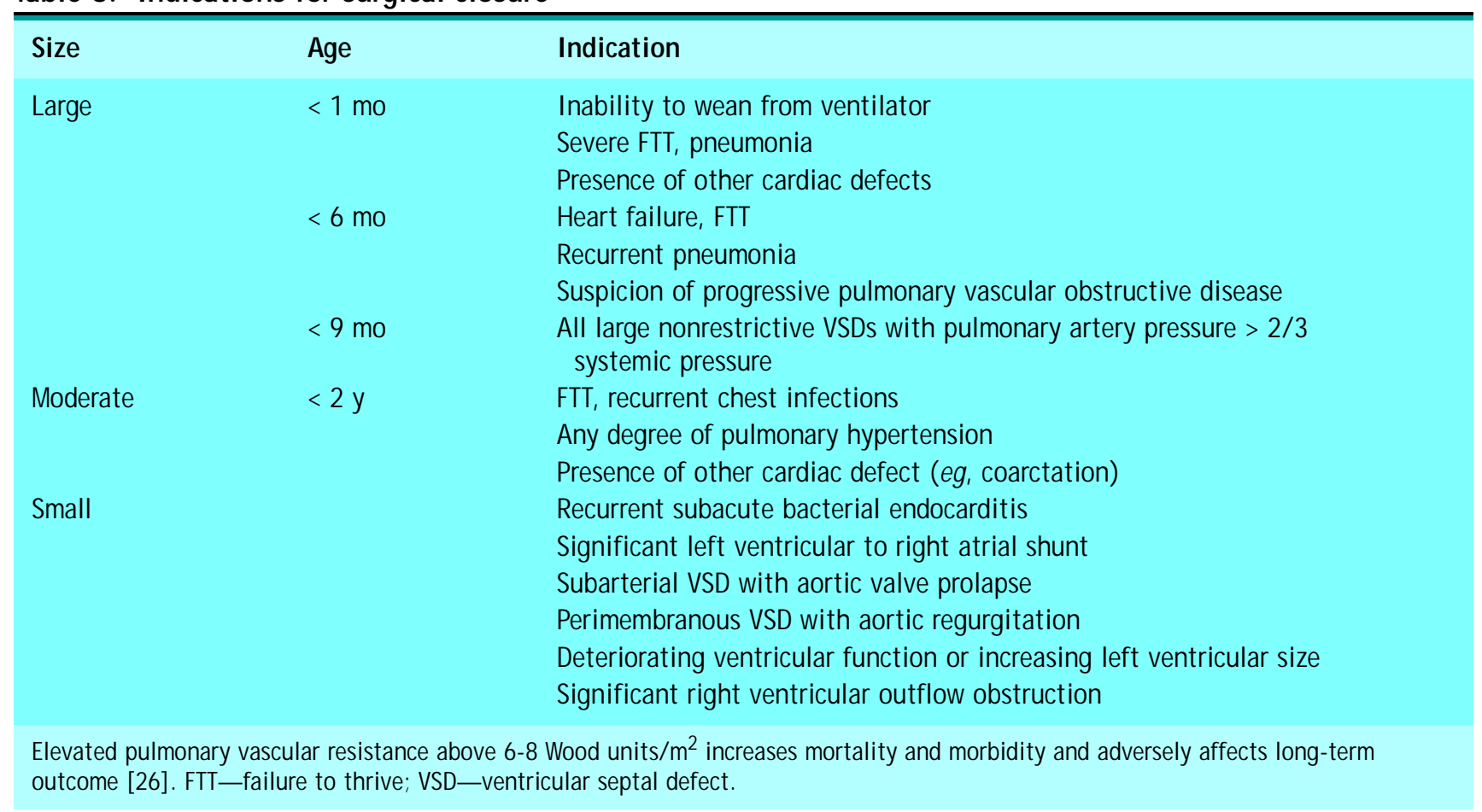

Cost/cost effectiveness Treatment with digoxin is used as a bridge to surgery, and its expense is therefore limited. Digitalis elixir in $60-\mathrm{cc}$ aliquots of $50 \mu \mathrm{g} / \mathrm{mL}$ can be obtained for about $\$ 20$. Digoxin tablets, $0.125 \mathrm{mg}$, cost about $\$ 10$ for 100 tablets.

\section{Surgery}

- Indications for surgery are listed in Table 3.

- Most isolated perimembranous, inlet, and muscular VSDs can be repaired through the right atrium, thereby avoiding the effects of a ventriculotomy.

- Inlet defects may require detachment of the septal leaflet of the tricuspid val ve to improve the exposure of the VSD.

- Defects in the outlet septum may be best visualized and dosed through the pulmonary artery. 
- Apical muscular VSDs may require a ventriculotomy at the apex of the left ventricle for adequate exposure to the VSD; however, this may compromise left ventricular function. For this reason, there is increasing interest in interventional devices to close muscular VSDs.

- Complete surgical correction is done with the patient under hypothermia on cardiopulmonary bypass at low flow with cannulation of the superior and inferior vena cava. Alternatively, in the smaller infant, deep hypothermia with total circulatory arrest is used.

- Pulmonary artery banding as a palliativestep to limit the pulmonary blood flow is very rarely indicated today. In the 1960s and even the 1970s, pulmonary artery banding was more popular as a temporizing operation to allow the infant to grow before definitive open heart surgery was done as a second staged operation. With the improvements over thelast three decades in surgi cal technique, cardiopulmonary bypass, anesthesia, and intensive care, one-stage VSD closure has been shown to be associated with improved outcome as compared with the two-stage approach [27]. Rarely, pulmonary artery banding is done for isolated VSD if there is ongoing pulmonary infection or if there are multiple or difficult apical muscular VSDs.

- The surgical mortal ity rate for VSD closure should be less than $3 \%$, although the mortality rate in the small infant with associated pulmonary and nutritional problems is somewhat higher $[28 \bullet \bullet, 29]$.

- Considerable advances have been made in the last decade in the intensive care management of the postoperative patient with a large VSD with pulmonary hypertension. When any degree of PVOD is suspected, a pulmonary artery catheter is placed through the right ventricular outflow tract to monitor pulmonary pressure and to manage "pulmonary hypertensive crises." Residual pulmonary hypertension is managed with sedation and paralysis with meticulous ventilation, keeping the $\mathrm{pCO}_{2}$ at 30 to $35 \mathrm{~mm}$ $\mathrm{Hg}$ and providing additional oxygenation. Inhaled nitric oxide has been shown to be a potent pulmonary vasodilator. If necessary, continuous administration with less than 20 ppm will effect an adequate reduction in pulmonary pressure [30].

\section{Physical/speech therapy and exercise}

- Children and adolescents with a small VSD can participate in all levels of physical activity so long as they have normal pulmonary artery pressure (peak systolic pulmonary artery pressure of less than $40 \mathrm{~mm} \mathrm{Hg}$ ) and no significant associated cardiorespiratory disorders.

- Athletes with moderate elevation of pulmonary pressure should avoid high-intensity sports until after surgical repair of the septal defect. Exercise testing and Holter ambulatory monitoring for unsuspected arrhythmias would be prudent before al lowing serious participation in competitive athletics.

- The presence of pulmonary vascular disease places the athlete at high risk for sudden death during exercise and prohibits partici pation in vigorous athletics.

- Full participation in competitive sports is permitted 6 months after successful repair of VSD. If residual shunting, pulmonary hypertension, ventricular dysfunction, or arrhythmia is present, further evaluation and some restriction of the level of athletic activity may be necessary [31 ••]. 


\section{Other therapies/ considerations}

\section{Insurability}

- Standard life insurance risk is assumed by most large insurers for patients who have undergone successful surgical closure of VSD and who have no residual hemodynamic or physiologic abnormalities. In some cases, a patient with a small unrepaired VSD is also considered in the normal-risk category.

- Patients with a residual or an unrepaired VSD with a volume-loaded left ventricle and moderate pulmonary hypertension have substandard life insurance risk with higher premiums.

- Patients with large VSDs or pulmonary vascular obstructive disease are uninsurable [32].

- Health insurance can be expensive and difficult to obtain if the patient is not al ready covered under a preexisting parental policy. Prepaid heal th plans are often a more accessible form of heal th coverage but may limit access to the special ists most knowledgeable in the care of this disorder.

\section{Pregnancy}

- Patients with a small or moderate residual or unrepaired VSD generally tolerate the hemodynamic stress of pregnancy without difficulty.

- An intermediate risk is posed to the mother's health if she has significant left ventricular volume overload and mild pulmonary hypertension.

- Women with New York Heart Association functional class III or IV heart disease with moderate or severely increased pulmonary vascular resistance or congestive heart failure have a very high risk of both maternal and fetal death [33].

- Endocarditis prophylaxis is not required for uncomplicated vaginal or cesarean delivery, al though if difficult delivery is anticipated or if associated higher-risk cardiac lesions coexist, antibiotic admi nistration at the onset of labor and for 3 to 4 days after delivery is recommended $[22 \cdot, 34]$.

\section{Genetic counseling}

- Another major concern for patients with VSD is the risk of passing VSD or another form of congenital heart disease to their offspring. For sporadically occurring isolated VSD, the recurrence risk has been estimated to be 3\% to $8 \%$ when the mother is the affected parent and 3\% if the father is the affected parent $[35,36]$.

- Fetal echocardiography at 20 to 22 weeks' gestation can be performed for evaluation of cardiac anomal ies in the fetus of a parent affected with a VSD.

- The use of nitric oxide has had a dramatic impact on the management of pulmonary hypertension in patients with congenital heart disease and PVOD, both in the initial preoperative assessment and in postoperative management. Preoperatively, patients with VSD and el evated pulmonary vascular resistance need to be evaluated to assess whether the changes in the pulmonary vascular bed are reversible Purel y increased muscularity of the vessel wall is considered reversible, whereas extensive intimal changes, obliteration, adventitial fibrosis, and a reduction in the number 
of intra-acinar arteries are considered irreversi ble Pulmonary vascular changes are suggested by 1 ) a response to inhaled nitric oxide, causing a decrease in the indexed pulmonary vascular resistance (PVRi) to less than 6 Wood units $/ \mathrm{m}^{2}$; 2) a decrease of the pulmonary-to-systemic resistance ratio (Rp/Rs) to less than 0.3 ; or 3 ) a decrease of PVRi or Rp/Rs of $10 \%$ [26]. The use of nitric oxide after cardiac surgery in patients with congenital heart disease and pulmonary hypertension is well described and has been discussed previously. The problem of rebound pulmonary hypertension after withdrawal of nitric oxide therapy has been a clinical issue Recent studies have suggested that the use of dipyridamole may attenuate the effect of nitric oxi de withdrawal [37]. New work suggests that nitric oxide may even cause vascul ar remodeling, thus decreasing the pulmonary vascular resistance Some patients with severe PVOD have been pretreated with inhaled nitric oxide for several weeks before surgery to remodel the pulmonary vascular bed and decrease pulmonary vascular resistance [38].

- Respiratory syncytial virus (RSV) infection with bronchiolitis causes significant morbidity and mortality during the winter months in infants with congenital heart disease, induding those with a large left-to-right shunt from a VSD [39]. An immuneglobul in was developed for monthly intravenous administration using a neutral izing polydonal antibody to RSV (RespiGam; Medimmune, Inc., Gaithersburg, MD). This has been used successfully in premature babies and in those with bronchopulmonary dysplasia to prevent RSV infection. An increase in mortality rate was noted, however, with the use of this preparation in infants with congenital heart disease, predominantly those with complex cyanotic heart disease The more recent devel opment of a monthly intramuscular injection of anti-RSV monoclonal antibody (palivizumab [Synagis; Medimmunelnc, Gaithersburg, MD]) is very promising [40], al though no data are available about the safety and efficacy of this product in children with congenital heart disease A multi-institutional double-blinded study in the United States of palivizumab in children with congenital heart disease has recently been completed. The outcome of this study is eagerly anticipated by pediatric cardiologists.

- Transcatheter closure of ventricular septal defects is a novel approach that may obviate the need for open heart surgery and cardiopulmonary bypass and thereby shorten the hospital stay. The procedure is done with the patient under general anesthesia with transesophageal echocardiographic guidance Several devices have been used, including the CardioSEAL Ocduder (Nitinol Medical Technologies, Inc., Boston MA), the Rashkind double umbrella (USCI, Billerica, MA), the Sideris button device (Custom Medical Devices, Amarillo, TX), and, more recently, the self-centering Amplatzer septal occluder (AGA Medical Corporation, Golden Valley, MN). Most of these devices are not available for general use in the United States but are under Food and Drug Administration (FDA) investigation at specific institutions. The CardioSEAL device has recently received FDA approval for use in closing VSDs that are not accessible transatrially or transarterially. The most promising indication for transcatheter device closure has been muscular VSD remote from the atrioventricular and semilunar valves. The apical muscular VSD, which is accessible to the surgeon only from an apical left ventricul otomy, is especially appropriate for this form of dosure. Device closure can be performed in the catheterization laboratory or even during the surgical procedure if there are other lesions requiring surgical correction [16]. Membranous defects have been closed using the Sideris button device when the distance from the center of the defect to theinsertion of theright coronary aortic leaflet wasmore than $50 \%$ of the size of the required device [41]. Perforation of the right aortic cusp was described in a case in which a Rashkind double umbrella was used [42]. 
- Minimally invasive cardiac surgery reduces incisional pain and shortens hospital stay. It has recently been applied to a variety of cardiac lesions, including VSD closure in patients older than 3 years [43]. The surgery is done using femorofemoral cardiopulmonary bypass and a left anterior minithoracotomy with video-assisted endoscopy. This surgical approach is still preliminary, but many surgeons are now also modifying their traditional techniques to use a shorter median sternotomy. This improves the cosmetic result on the anterior chest wall while still employing the conventional procedure of cardiopulmonary bypass and surgery.

\section{References and Recommended Reading}

Papers of particular interest, published recently, have been highlighted as:

- Of special interest

-. Of outstanding interest

1. USDepartment of Health and Human Services: Ventricular septal defect. M M WR M orb M ortal W kly Rep 1981, 30:609-610.

2. • Gumbiner $\mathrm{CH}$, Takao A: Ventricular septal defect. In The Science and Practice of Pediatric Cardiology, edn 2. Edited by Garson A, Bricker JT, Fisher DJ, Neish SR. Baltimore: Williams \& Wilkins; 1998.

An excellent, comprehensive, and up-to-date summary of the diagnosis and management of ventricular septal defect.

3. King ME: Echocardiographic evaluation of the adult with unoperated congenital heart disease. In The Practice of Clinical Echocardiography. Edited by Otto CM. Philadelphia: W.B. Saunders Co.; 1997.

4. Kardon RE, Cao QL, Masani N, et al.: New insights and observations in three-dimensional echocardiographic visualization of ventricular septal defects: experimental and clinical studies. Circulation 1998, 98:1307-1314.

5. Magee AG, Boutin C, McCrindle BW, Smal Ihorn JF: Echocardiography and cardiac catheterization in the preoperative assessment of ventricular septal defect in infancy. Am H eart J 1998, 135:907-913.

6. Mitchell SC, Korones SB, Berendes HW: Congenital heart disease in 56,109 births. Circulation 1971, 43:323-332.

7. MoeDG, Guntheroth WG: Spontaneous closure of uncomplicated ventricular septal defect. Am J Cardiol 1987, 60:674-678.

8. Neumayer U, StoneS, SomervilleJ: Small ventricular septal defects in adults. Eur H eart J 1998, 19:1573-1583. A long-term follow-up of adults with small ventricular septal defects that examines the consequences of long-standing shunt flow.

9.・ Gersony WM, Hayes CJ, Driscoll DJ, et al.: Bacterial endocarditis in patients with aortic stenosis, pulmonary stenosis, or ventricular septal defect. Circulation 1993, 87( suppl I):I121-I126.

This entire supplement reports the results of the second natural history study of children with aortic and pulmonic stenosis and ventricular septal defect. It includes data on natural history, echocardiography, exercise performance, recurrence rates, and endocarditis risk.
10. Driscoll D, Allen HD, Atkins DL, et al.: Guidelines for evaluation and management of common congenital cardiac problems in infants, children, and adolescents. Circulation 1994, 90:2180-2188.

This is a statement from the American Heart Association Committee on Congenital Cardiac Defects with evaluation and management algorithms for children with uncomplicated small ventricular septal defects.

11. Schmidt KG, Cassi dy SC, Silverman NH, Stargen P: Doubly committed subarterial ventricular septal defects: echocardiographic features and surgical implications. J Am Coll Cardiol 1988, 12:1538-1546.

12. Weidman WH, Blount SG, Dushane JQ, et al.: Clinical course in ventricular septal defect. Circulation 1977, 56(suppl I):I56-I59.

13. Yeager SB, Freed MD, KeaneJF, et al.: Primary surgical closure of ventricular septal defect in the first year of life: results in 128 infants. J Am Coll Cardiol 1984, 3:1269-1276.

14. Chang AC, Hanley FL, LockJE, et al.: Management and outcome of low birth weight neonates with congenital heart disease. J Pediatrics 1994, 3:461-466.

15. Kirklin JW, Appelbaum A, Bargeron LM Jr.: Primary repair versus banding for ventricular septal defects in infants. In The Child with Congenital H eart D isease after Surgery. Edited by Langford-Kidd BS, Rowe RD. Mount Kisco, NY: Futura; 1976.

16. Bridges ND, Perry SB, Keane JF, et al.: Preoperative transcatheter closure of congenital muscular ventricular septal defects. N Engl J M ed 1991, 19:1312-1317.

17. Fishberger SB, Bridges ND, Keane JF, et al.: Intraoperative device closure of ventricular septal defects. Circulation 1993, 88(suppl II):III205-II209.

18. LockJE, Einzig S, Bass JL, Moller JH: The pulmonary vascular response to oxygen and its influence on operative results in children with ventricular septal defect. Pediatr Cardiol 1982, 3:41-46.

19. Roberts JD, Lang P, Bigatello LM, et al.: Inhaled nitric oxide in congenital heart disease. Circulation 1993, 87:447-453. 
20. Yahav J, Avigad S, Frand M, et al.: Assessment of intestinal and cardiorespiratory function in children with congenital heart disease on high-caloric formulas. J Pediatr Gastroenterol N utr 1985, 4:778-785.

27. Talner NS: Heart failure. In M oss' H eart D isease in Infants, Children, and Adolescents, edn 4. Edited by Adams $\mathrm{FH}$, Emmanouilides GC, Riemenschneider TA. Baltimore: Williams \& Wilkins; 1989.

22. $\bullet$ Dajani AS, Taubert KA, Wilson W, et al.: Prevention of bacterial endocarditis: recommendations by the American Heart Association. JAM A 1997, 277:1794-1801.

The most updated American Heart Association guidelines for bacterial endocarditis prophylaxis.

23. Sluysmans T, Stryns-Cailtus $M$, Tremourous-Wattiez $M$, et al.: Intravenous enalapril and oral enalapril in congestive heart failure secondary to ventricular septal defect in infancy. Am J Cardiol 1989, 70:959-962.

24. Kimball TR, Daniels SR, Meyer RA, et al.: Effect of digoxin on contractility and symptoms in infants with a large ventricular septal defect. Am J Cardiol 1991, 13:1377-1382.

25. Boerth RC: Decreased sensitivity of newborn myocardium to the positive inotropic effects of ouabain. In Basic and Therapeutic Aspects of Perinatal Pharmacology. Edited by Morselli PL, Garattini S, Sereni F. New York: Raven Press; 1975.

26. Berner M, Beghetti M, Spahr-Schopferl, et al.: Inhaled nitric oxide to test the vasodilator capacity of the pulmonary vascular bed in children with longstanding pulmonary hypertension and congenital heart disease. Am J Cardiol 1996, 77:532-535.

27. Kirklin JW, Appelbaum A, Bargeron LM: Primary repair versus banding for ventricular septal defects in infants. In The Child with Congenital H eart D isease after Surgery. Edited by Langford-Kidd BS, Rowe RD. Mount Kisco, NY: Futura; 1976:3-9.

28. • Castaneda AR, JonasRA, Mayer JE, Hanley FL: Ventricular septal defect. In Cardiac Surgery of the N eonate and Infant. Edited by Castaneda AR, Jonas RA, Mayer JE, Hanley FL. Philadel phia: W.B. Saunders Co.; 1994:187-201.

A thorough textbook discussion of the surgical management of ventricular septal defect.

29. Reddy VM, McElhinney DB, Sagrado T, et al.: Results of 102 cases of complete repair of congenital heart defects in patients weighing $\mathbf{7 0 0}$ to 2500 grams. J Thorac Cardiovasc Surg 1999:117(2):324-331.

30. Miller O, Celermajer DS, Deanfield JE: Very low dose inhaled nitric oxide: a selective pulmonary vasodilator after operations for congenital heart disease. J Thorac Cardiovasc Surg 1994, 108(3):487-494.
31.• Graham TP Jr., Bricker JT, James FW, Strong WB: 26th Bethesda conference: recommendations for determining eligibility for competition in athletes with cardiovascular abnormalities. Task Force 1: congenital heart disease. J Am Coll Cardiol 1994, 24:867-873.

An excellent consensus conference report cosponsored by the American College of Cardiology and the American College of Sports Medicine It reviews the recommendations for participation in sports activities by patients with cardiovascular abnormalities. The report of Task Force 1 discusses specific issues related to congenital heart disease

32. Mahoney LT, Truesdel ISC, Hamburgen M, Skorton DJ: Insurability, employability and psychosocial considerations. In Congenital H eart D isease in Adults. Edited by Perloff JK, Child JS. Philadelphia: W.B. Saunders Co.; 1991.

33. Perloff JK: Congenital heart disease and pregnancy. In Principles of M edical Therapy in Pregnancy. Edited by Gleicher N. New York: Plenum Medical Books; 1985:665-671.

34. Canobbio MM: Counseling the adult with congenital heart disease In Adult Congenital H eart Disease. Edited by Roberts WC. Philadelphia: F.A. Davis Co.; 1987:733-739.

35. Nora J, Nora AH: Maternal transmission of congenital heart disease: new recurrence risk figures and the questions of cytoplasmic inheritance and vulnerability to teratogens. Am J Cardiol 1987, 59:459-463.

36. Driscoll DJ, MichelsW, Gersony WM, et al.: Occurrence risk for congenital heart defects in relatives of patients with aortic stenosis, pulmonary stenosis, or ventricular septal defect. Circulation 1993, 87(suppl I):I 114-I120.

37. Ivy DD, Kinsella JP, Ziegler JW, et al.: Dipyridamole attenuated rebound pulmonary hypertension after inhaled nitric oxide withdrawal in post operative congenital heart disease. J Thorac Cardiovasc Surg 1998, 115(4):875-882.

38. Del Nido P: Personal communication.

39. MacDonald NE, Hall CB, Suffin SC, et al.: Respiratory syncytial virus infection in infants with congenital heart disease. N Engl J Med 1982, 307:397-400.

40. American Academy of Pediatrics Committee on Infectious D iseases and Committee of the Fetus and Newborn: Prevention of respiratory syncytial virus: indications for the use of palivizumab and an update on the use of RSV-IGIV. Pediatrics 1998, 102:1211-1216.

41. Sideris E, Walsh KP, Haddad J, et al.: O cclusion of congenital ventricular septal defects by the button device. H eart 1997, 77(3):276-279.

42. Vogel M, Rigby ML, Shore D: Perforation of the right aortic cusp: complication of septal defect closure with a modified Rashkind umbrella. Pediatr Cardiol 1996, 17(6):416-418.

43. Ling PJ, Chang $\mathrm{CH}, \mathrm{Chu} \mathrm{J}$, et al.: Minimally invasive cardiac surgical techniques in the closure of ventricular septal defect: an alternative approach. Ann Thorac Surg 1998, 65:165-170. 